\title{
Development and Application of Real-Time Bridge Scour Monitoring System
}

\author{
Joongu Kang \\ Department of Water Resources Research, Korea Institute of \\ Construction Technology, Goyang City, Korea \\ E-mail: jgkang02@kict.re.kr \\ Received July 6, 2011; revised August 4, 2011; accepted August 22, 2011
}

\begin{abstract}
Because of the complex nature of the changes in the current and movement of the riverbeds by bridge scouring, it is impossible to understand or predict these changes. In order to have a reliable data, it is critical to have the current methods and equipment for measuring bridge scouring replaced with technology that could acquire real-time bridge scouring data. Despite the critical need for real-time data acquisition, the harsh environmental conditions have prevented the scientific community from acquiring real-time data. Harsh environmental conditions were addressed by the developmental of an automated, remote data collection system, allowing real-time data such as scour movement, scour depth, and scour trend to be viewed in a safe location. As a result, accurate sea-floor movements were seen for the first time, aiding the direction and future of bridge scour research, ultimately contributing greatly to the safety of bridges.
\end{abstract}

Keywords: Bridge Scour, Real-Time, Data Acquisition, Monitoring System

\section{Introduction}

Traditional scour research relied mostly on lab simulation tests. The simulations posed great difficulties in providing reliable data as the materials and variables could not be consistent or controlled. In most simulations, insignificant factors were ignored to concentrate on the major factors. The simulations were limited to measuring the maximum scour bed changes. For a more efficient and in-depth study in scour research, a real-time scour measurement system was needed.

Despite the critical need for a real-time scour measurement system, the limitations of technology in a difficult environment for scour measurement have prevented the advancement of a real-time scour measurement system. Since scour bed changes in rivers are created during high water flood conditions and rapid water movements that cause muddy water mixtures, safely obtaining scour bed measurements in real time has been impossible. The measurements are therefore taken after flood conditions, or during calm tidal waves for oceanic bridges. These measurements are taken well after the most violent scour bed changes, making the data virtually useless in monitoring scour bed movement.

The purpose of this research was to address these is- sues by developing a scour measurement system that is unmanned, remote-controlled, and performed in realtime. The research was then tested in oceanic bridges to prove its efficiency and reliability. By remotely obtaining and analyzing data sent in real time, monitoring scour bed changes, water depth changes, and scour behavior became a reality.

\section{Development of the Real-Time Bridge Scouring Data Acquisition \& Monitoring System}

The real-time bridge souring data acquisition \& monitoring system was developed to satisfy the ultimate goal of analyzing the actual quantitative bridge scouring measurements in bridge scour research. By combining a bridge scouring data acquisition system and a communication system, monitoring the bridge scouring data in real time brought a new dimension in bridge scour research.

\subsection{Developmental Conditions for the Real-Time Bridge Scouring Data Acquisition \& Monitoring System}

In order for a new system to be developed, the system 
must not only address the current problems, but also reflect the environmental conditions of the installation site at the same time. The basis of the research and field study can be seen from the following developmental conditions of the system:

1) The system must be able to continuously monitor the bridge scouring data under any harsh environmental conditions.

2) The system must be able to evaluate bridge scouring data from an accurate plane.

3) The monitoring must be done in real-time.

4) The system must be universal, used in rivers to oceans.

5) The system must contribute to the safety of bridges by providing a direction in bridge construction.

To address the conditions above, the following measurements were taken. First, an automated bridge scouring sensor located above the water can be used to acquire data under any conditions, unmanned. Second, a remote data inquiry and controller can provide data from an accurate plane. Third, the real-time data can be acquired from an automated system that can provide a simpler and a smoother acquisition process. Fourth, a new scouring sensor (SM200) that was developed by using supersonic wave distance sensors is used anywhere, from rivers to oceans. Fifth, the real-time data can be stored in a database for analysis and instant monitoring of scouring data for bridge safety.

\subsection{Field System Composition}

Figure $\mathbf{1}$ is a diagram of the field system concept. The field system is composed of four major elements: the electrical power supply source, data collection equipment, scour measuring equipment, and the data communication equipment. The power source is run by both battery and solar power. Solar power is used and stored during the daytime, and the charged battery is used during the night time. The heart of the system is the data logger, a small computer that processes the data acquired in real-time from the sensors. The most appropriate and safe sensor

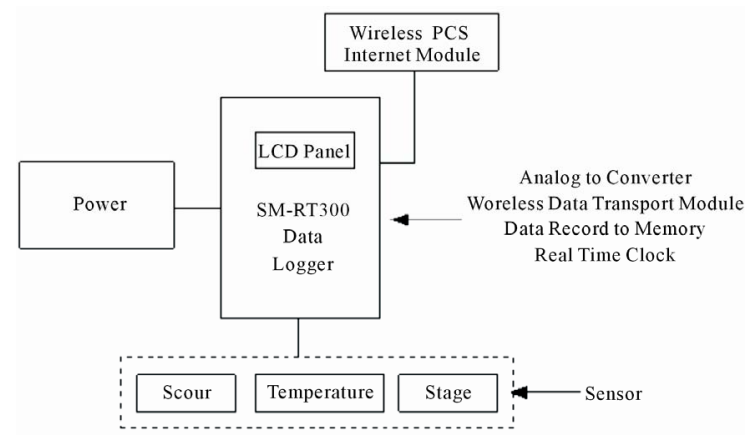

Figure 1. Block diagram of scour monitoring system. was selected for both river and oceanic scour measurements, although any type of sensor could be used in the scour meter. The data is communicated through a wireless PCS phone.

\subsection{Power Supply}

To acquire an accurate and credible data, a safe and continuous power supply must be provided. In case of an unstable power source in the field, the following measurements were taken in the design:

- Field locations where power can be provided.

If the system is installed in a field where the electricity can be provided ( $220 \mathrm{v}$ or $110 \mathrm{v})$, the system can be equipped with a regulator that converts the current to the necessary $12 \mathrm{v}$ and a DC-DC converter that converts the $12 \mathrm{v}$ to $15 \mathrm{v}$. The DC-DC $15 \mathrm{v}$ converter is required due to the voltage requirement in other equipment. An additional re-chargeable battery is connected in case of a power outage.

- Field locations where the power supply is difficult.

In most locations, a stable and continuous supply of power cannot be expected. A re-chargeable battery can be used to power the system. Because most of the equipment in the system uses $12 \mathrm{v}$, common batteries that can be easily bought in retail stores can be used. Solar panels are also used to charge the battery during the daytime, and the charged batteries are used during the nighttime. The solar power charging system was designed to charge and supply power during the daytime.

\subsection{Data Acquisition System}

An unmanned and remote control of the field system requires a processing system. In this research, a Palmtop PC (Personal Computer) and a PICBASIC2000 computer were used. The compact Palmtop PC is effective due to its small electrical power consumption, and large hard drive disk space for storage. Other external accessories can be plugged into the Palmtop PC's serial and parallel ports, speeding up the data acquisition and eliminating the need for external connecting hardware. The PICBASIC2000 has limited abilities compared to the Palmtop PC, but it can perform all the necessary data processing, data storage, communication, control of the attached accessories, and consume less power than the Palmtop PC. The PICBASIC2000 is ideal for long term data monitoring and acquisition.

The signals from the sensors come in a form of a continuous analog signal, caused by the resistance in the electrical pressure [1,2]. In most cases, these signals become unreliable due to the static and the weakness of the signal as it becomes digitally converted through an elec- 
trical circuit in its final phase.This process is called "Signal Conditioning” [3]. Figure 2 represents the process from the natural, physical quantities to the input in the computer. For a computer to process the natural data, it must go through Signal Conditioning and be changed in the necessary state. The semiconductor in the computer that performs this process is called the A/D Chip (Analog-to-Digital Converter Chip). The A/D Chip maintains a 5 volt electrical pressure, and the electrical pressure changes in the standard 5 volts caused by the analog signals converts the analog signals into digital signals. It is critical for the A/D Chip to maintain an accurate and a continuous 5 volts [2]. The majority of the latest A/D Chips employ multiplexers that can handle multiple sensor inputs. Based on the number of the input sensors, 4, 8, or 16-input A/D Chips can be used, and because the multiplexer doesn't require an independent circuit, the simplicity provides more reliability and the size allows the system to be small.

There are two factors in A/D Chips that must be considered before choosing the right chip: the analyzing ability, and the speed of change. The analyzing ability is how efficient the chip senses the changes (Fraden, 1993). The analyzing ability is measured in bits, if the analyzing ability is 1 bit, it represents 21 ratios in its selection. If the analyzing ability is 12 bit, a maximum of $1000 \mathrm{~g}$ equals 4096 (212) levels of load that can be represented and it means that 1000/4096 (approx. $0.2 \mathrm{~g}$ ) minimal analyzing ability can be achieved. The speed of change is the rate of change measured in 1 second, and selecting the appropriate A/D Chip Converter depends on the quantitative amount of changes. Voice recognition, automobile crash test analyses are an example of requires an $A / D$ Chip that can analyze mass data in a short amount of time. Formost civil engineering cases, the rate of change is more gradual and slow that the $\mathrm{A} / \mathrm{D}$ Chip can be a down to a few hertz per second. (Yeo et al., 1997) Selecting the most appropriate A/D Chip for Civil/ Environmental Engineering depends on the analyzing ability, energy consume rate, and convenience instead of the

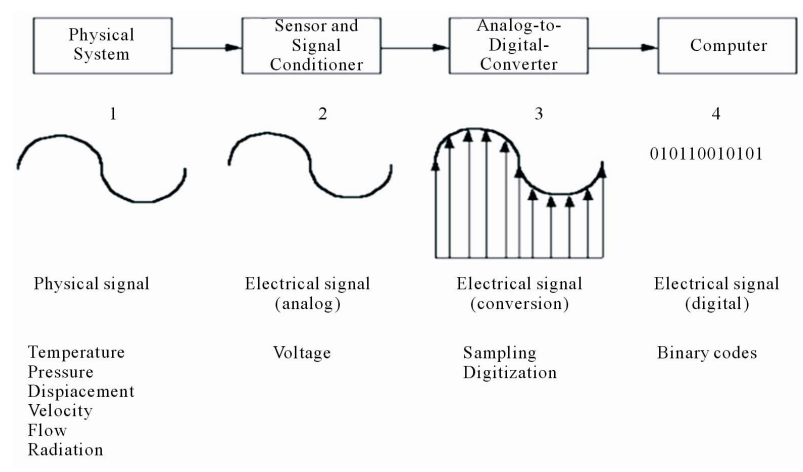

Figure 2. Block diagram of data acquisition process. speed of change. A chip with a high rate of analyzing ability can be useful in its ability to detect the smallest changes; however, as the speed of change becomes slower, the energy consumption becomes greater, and the complexity of the circuit becomes greater, it is essential to review all the capabilities. For this research, an in house PPDL12 [4] was developed, using a 12bit A/D Chip.

\subsection{Scour Meter Sensor}

There are various types of Scour meter sensors such as, the breaker-switch type, vibration acceleration type, GPR, TT, and the black and white sound measurement type. There are advantages and disadvantages to each different type of sensor; however, a sensor that could sense the constant scour changes in both flood rivers and oceanic salt water is necessary. A supersonic wave distance sensor is perfect for this requirement. The supersonic wave sensor uses electrical sound pluses in the water and measures the time it takes to bounce back from the floor. It is critical to study the sound wave behavior in the body of water to understand the characteristics, function, and the limitations of the supersonic wave sensor. The speed of the sound wave in the water travels at $1450.1530 \mathrm{~m} / \mathrm{s}$, different from the sound wave in air. There are many factors in determining the speed of sound waves in water, temperature being the most critical. To measure an accurate reading from the sound waves in the water, the water temperature must be in consideration. Formula (1) represents the formula for sound wave speeds.

$$
\begin{aligned}
& C=1449+4.95-0.053 T 2+0.0163 D \\
& c=\text { speed of sound in water }(\mathrm{m} / \mathrm{s}) \\
& t=\text { water temperature } \\
& d=\text { water depth }(\mathrm{m})
\end{aligned}
$$

In bodies of water where the water temperature is constant, the speeds of electronic sound waves are constant as well. Consequently, when calculating the time for electronic sound waves, the sound waves are the shortest traveling distance. When $c$ represents the speed of sound, and $t$ represents the time it takes for the sound wave to travel from the starting point to the return after bouncing from the floor, the distance $(\mathrm{L})$ from the sensor to the ocean floor can be calculated in Formula (2):

$$
L=c \quad t / 2
$$

When the sensor repeatedly measures the depth at a given period time, the depth changes can be monitored, thus allowing the scouring changes on the floor to be monitored. Figure 3 shows a map of the changing scour depth measured by the sound wave distance sensor. The Pigeot valve is commonly used for the heart of the Scour 


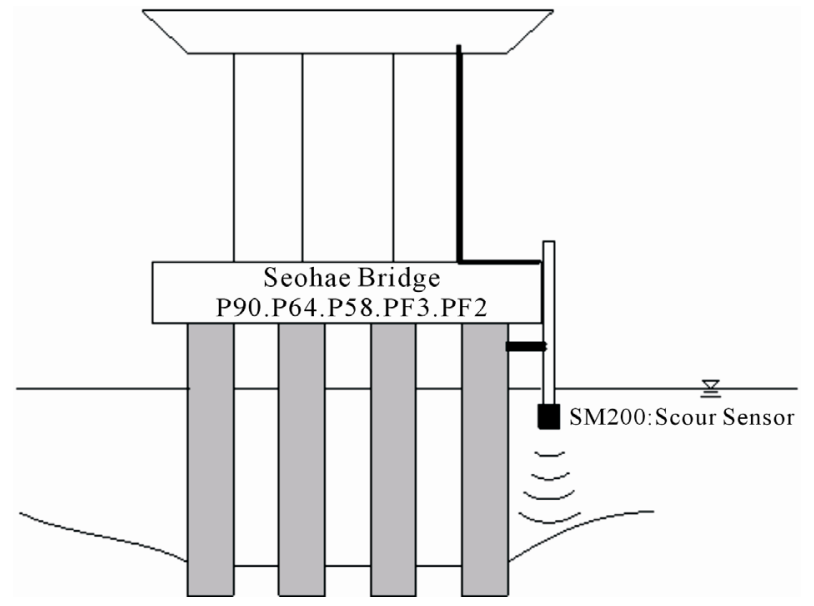

Figure 3. Composition of Scour sensor.

meter sensor, where the electronic pulse is converter into a vibrating valve. The frequency of the valve openings depend on the given electronic signals, making the vibration frequency consistent and controllable. In most cases, the sound frequency under water ranges from a few $\mathrm{kHz}$ to a few hundred $\mathrm{kHz}$. The characteristics of the electronic waves depend on the frequency. For instance, an electronic wave with a few $\mathrm{kHz}$ penetrates the floor surface and is ideal for studying geological stratum. In contrast, an electronic wave with a few hundred $\mathrm{kHz}$ is sensitive to the floor and immediately bounces off, and is ideal for monitoring detailed surface changes on the floor. The wavelength is the main cause for the difference.

The SM200 Bridge Scour meter sensor selected for research is a supersonic wave distance sensor that uses a thoroughly tested transducer to ensure the highest quality at $200 \mathrm{kHz}$ running frequency. The transducer is made from polyurethane materials with a diameter of $59 \mathrm{~mm}$ in a cylindrical form. Because the reflected signal from the transducer is too weak, it is magnified 800 times through an amplifying circuit and filtered from the noise picked up by the reflected signal. The next step is to monitor the time it takes for the signal to be reflected back and be compared to the standard depth.

The final output time is communicated wireless to the host computer through a RS-422 bus. Table 1 represents the SM200 Scour meter's specification.

\subsection{Data Communication System}

Field locations where the measuring system is installed are often out of human reach due to the climate and construction. A long distance data collection system was therefore needed.

The wire and wireless system are the two major methods for collecting data from a long distance. A wire system can use an ordinary phone line; however, most
Table 1. SM200 Scour meter's specification.

\begin{tabular}{cc}
\hline Devision & Range \\
\hline Range & $0.6 \sim 60 \mathrm{~m}$ \\
Accuracy & $0.3 \%, 2 \mathrm{~mm}$ \\
Output Type & RS-422 Digital \\
Resolution & $1 \mathrm{~mm}$ \\
Cable Length & Max $200 \mathrm{~m}$ \\
Frequency & $200 \mathrm{kHz}$ \\
Beam Angle & $7.5^{\circ}$ \\
Power & DC $12 \mathrm{~V}$ \\
Temperature & $-30^{\circ} \mathrm{C} \sim 60^{\circ}$ \\
\hline
\end{tabular}

field locations prevent long phone lines to be installed. For this research, the long distance data collection was concentrated solely in the wireless system.

Traditionally, wireless data has been collected through a satellite or a private telemeter net; however, wireless data collection must go through a difficult process of obtaining a frequency permit and has a very high cost in installation and usage. Additionally, the majority of the wireless modems in Korea is imported and is different from the standard frequency in Korea, making it impossible to use [5]. These issues are addressed by the use of a PCS wireless data communication service in this research. The PCS units receive constant quality control from its service provider and can transfer data at a maximum of 14,400 bps, providing not only a reliable and an accurate data communication, but also low cost in its development and usage. The advantages of a PCS communication network can be seen from the following:

First, compared to other wireless communication methods, the data transfer rate is superior. Satellites transfer data at $2400 \mathrm{bps}$, wireless modems at $9600 \mathrm{bps}$, telemeter systems at 1200 to 2400 bps, while the PCS phone can transfer data at $14,400 \mathrm{bps}$, and a maximum of 58,600 bps with the latest technology.

Second, the initial investment is low. PCS systems can be purchased at a few hundred dollars while other systems can start from a few thousand dollars to tens of thousands of dollars.

Third, the PCS units can be replaced immediately and any damage recovery can be made swiftly.

Fourth, data reliability is superior. The PCS network is extensive and the service providers constantly monitor quality control, making the data communication accurate and have a guaranteed quality. 
Fifth, the PCS phones have government approved frequency communication, and it can be used by anyone without a frequency permit.

Management System Composition

The management system is a program that allows fast and convenient data analyzing for the user. The management system is composed of software and network, and it is recommended that the management system is a program that can be installed and operated. Figure $\mathbf{4}$ represents the management system graphically.

The management system is mainly composed of two parts: input/output data acquisition through a wireless internet web program, and a management program that can analyze/store the data real-time in a database. The wireless internet program is a program designed to collect data at the site and provide a fast on-demand data for the users through the internet in real time. The management program then collects data and places it into two places: an analyzing program, and a server for providing data to the users. When the management program places the data into the analyzing program, it is analyzed through lab computers and provides graphs and databases. When the data is placed into the server, it is analyzed on the web, and can be accessed by clients through conventional internet.

\subsection{Wireless Internet Program}

The wireless internet program provides connection and remote control between each PCS wireless modems installed on each pier. Figure 5 represents an example of a common program, which is also the main focus of the network program. This wireless internet program is responsible for networking each PCS wireless systems, and the physical measurement from each pier is transferred in two methods: the transfer method which logs on to the internet to record "packet-transferred" data from the data logger on a set time schedule, and the method of logging onto the circuit at the site and requesting data on a set time schedule. This wireless internet program is able to

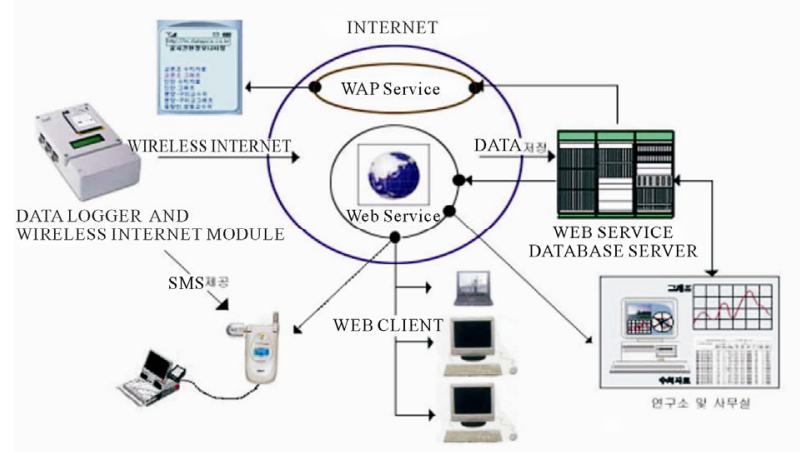

Figure 4. Realtime data control system and Internet server.

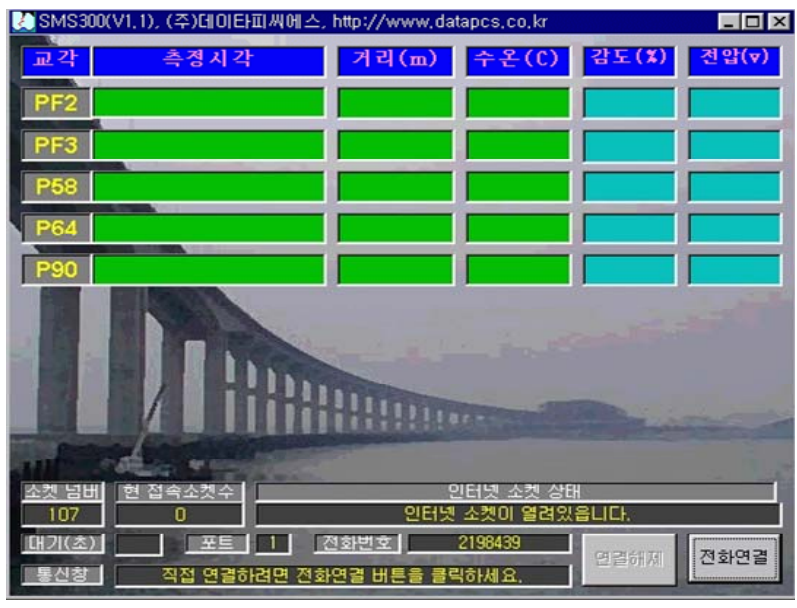

Figure 5. Internet program.

perform both transfer methods simultaneously, and can also provide data on-demand at any time or be custom-programmed to sample the data at a given time.

\subsection{Scour Management Program for Analysis}

The scour management program is designed to smoothly and conveniently provide real-time analyzed data to the user in the office. The sequence of the program can be summarized up in two steps, the storage of the raw text-file data, and creation of a database through several internal data filtration for ease of use. In addition, the data in the database is automatically converted into graphs for anyone to monitor

Figure 6 represents a text-file being filtered and converted into statistical data in a database. The user can not only choose to monitor different piers in any given time period, but the user can also see the data in both the physical state, or as a graph. The latest bridge scouring data can also be monitored, allowing real-time interpretation. The program designed for this study is constructed as one unit, but can be broken into three independent programs: a VB program, MySQL database program, and a Dataviews graphic program.

Figure 7 is a simplified drawing of the piers and the changing scour data that is being compared to the average data logged in the previous year. The real time monitoring also allows adequate time for preventative measures in case of an emergency.

\section{Coastal Bridge Application of Real-Time Bridge Scour Measuring System}

For coastal bridge scour observation, Seohae (East Sea) Bridge located at A-San Bay was chosen. The tidal difference, which is about $9.3 \mathrm{~m}$, creates a big current velocity. Also, due to the change in flow direction created 


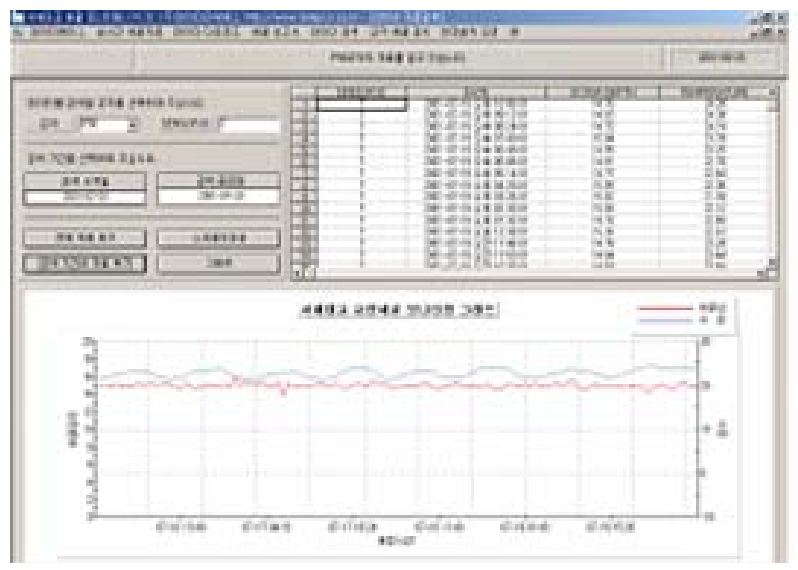

Figure 6. Database of field data.

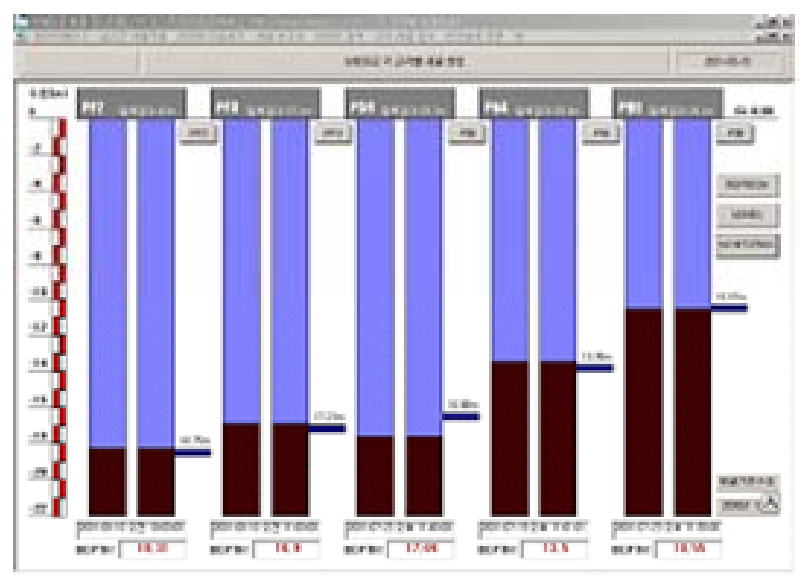

Figure 7. Example screen from scouring control system.

by continuous development of the bay, quite a big scale of the landform transformation has occurred. Because of these natural and artificial changes applied to this bay, long/short period of real-time measurement was needed to determine the actual bridge-scouring progress. Since the bed elevation which was measured prior to the construction started to decrease rapidly as the construction began, a close examination of scouring was required around piers

\section{Site and Location for Installation}

Seohae Bridge, which is $7310 \mathrm{~m}$ by $31.4 \mathrm{~m}$, connects two small towns across A-San Bay. The detailed site is illustrated in Figure 8.

The A-San Bay, where Seohae Bridge is located, has tidal difference over $9 \mathrm{~m}$, and its subaqueous bed, made of silt and send, has the geological bed structure that could be largely affected by scouring. The maximum flow velocity in field measured about $2.7 \mathrm{~m} / \mathrm{s}$. This region is very weakened by scouring caused by the tidal effect which occurs twice a day. The locations of installing scour sensors are a bit different each year, but PF2,
PF3, P58, P64, and P90 which exposed the local characteristics were chosen to install the sensors. These piers were where scouring was proceeding considerably, and these piers were chosen by the result obtained from experiments and numerical model. Figure 9 shows piles at bottom of piers on which the sensors are installed. Figure 10 demonstrates when the scour measure system was being installed.

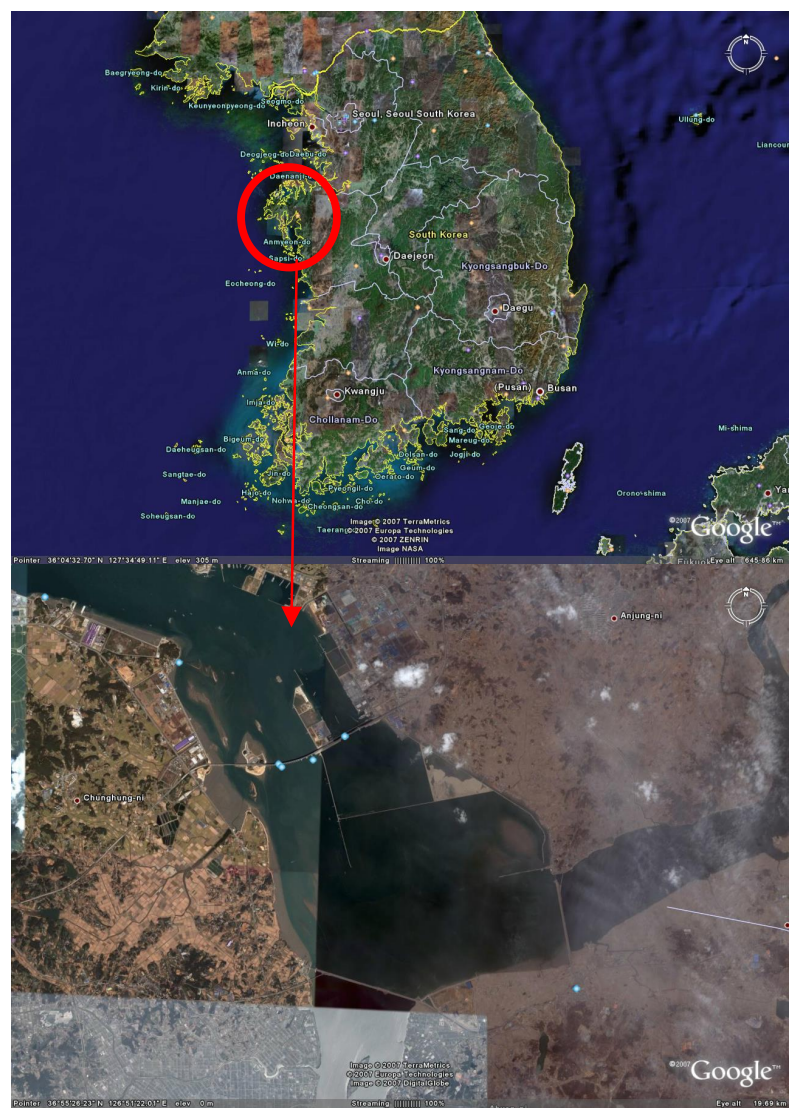

Figure 8. Site of Seohae Bridge.

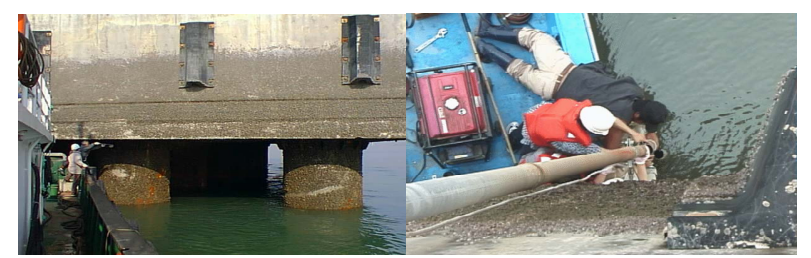

Figure 9. Pier shape of bridge and installation of scour sensor on the pier.

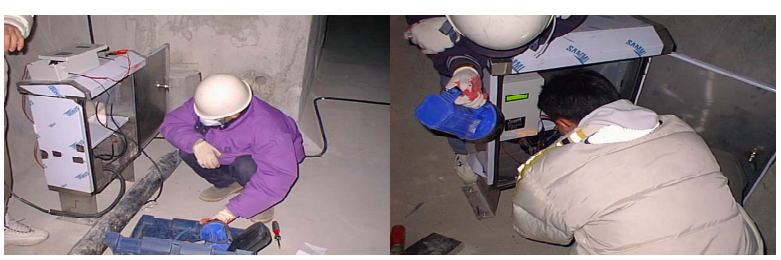

Figure 10. SMS at Seohae Bridge. 


\section{Acquiring Data}

Due to the scouring, which is caused by rapid tidal currents during the construction of embankment near Seohae Bridge, the use of the real time scour measurement system was necessary for observing the status of scouring for a long period of time. Since the initial scour generated by rapid tidal current's velocity was uncertain whether it was caused by the structures nearby or general scour created by revetment, the real time scour measurement system needed to catch even a tiny difference in the process of scour during the construction.

Considering the characteristics of the supersonic wave, and the reliability of the system, the analyzed final data were extracted. At first, the time unit of second was to be used to measure the variation of wave height, but since the amount of variation was quite insignificant, bigger unit of time had come in use for analyzing the change in scour depth using averaging data. To analyze the data, the period of tide had to be considered because A-San Bay was largely affected by the tide. The average period of tide in A-San Bay is about 12.24 hours. To perceive even very small changes in phase from scour data, at least 8 times of the general engineering minimum timing gap was recommended, so for filtering the data, it required at least the data of 4 days. There are six subjected piers, and in this paper, the data of only the main piers were provided. Figure 11 shows scour change in P2. Bed change varies between $16.5 \mathrm{~m}$ and $17.0 \mathrm{~m}$ and the fluctuation of scouring generated about $50 \mathrm{~cm}$. The reason of the fluctuation happened corresponded the tidal period. Figure 12 shows scour change in P3. Bed change varies between $17.4 \mathrm{~m}$ and $17.0 \mathrm{~m}$ and the fluctuation of scouring generated about $10 \mathrm{~cm}$. Figure 13 shows scour change in P64. Bed change varies between $13.8 \mathrm{~m}$ and $13.5 \mathrm{~m}$ and the fluctuation of scouring generated about $20 \mathrm{~cm}$. In cases of P2 and P64, the scour continuance could not be found. As a result, accurate sea-bed movements were seen for real time. Acquiring data could be important scour data for the safety of bridges.

\section{Conclusions}

In order to address the difficulties in monitoring bridge scouring data, a real-time bridge scouring data acquisition/monitoring system was developed, installed, and executed long-term in both river and oceanic bridges. The results from the river and oceanic bridge can be seen from the development and use of the real-time bridge scouring data acquisition system in (2) and (3). The effectiveness of the system can be seen through the acquisition of reliable data from the system over a long period of time. The following are a brief summary of the results.

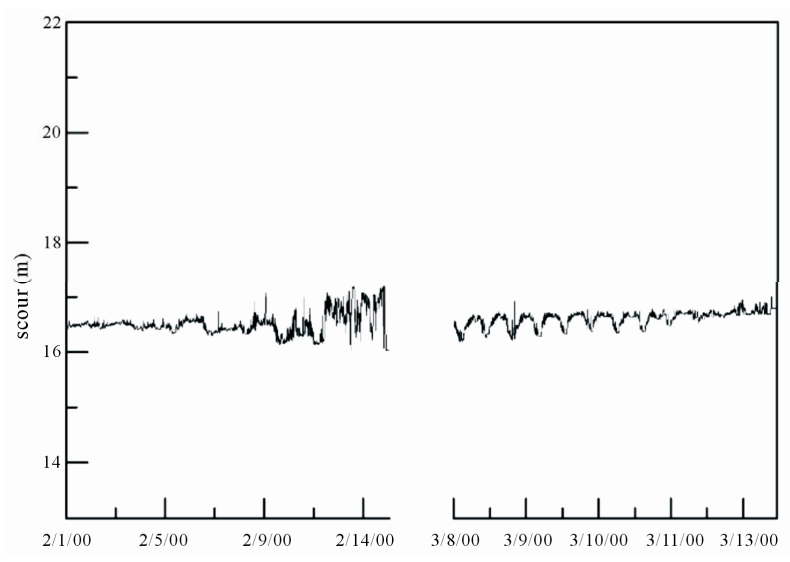

Figure 11. Scour depth variation at the pier $\mathbf{P} 2$.

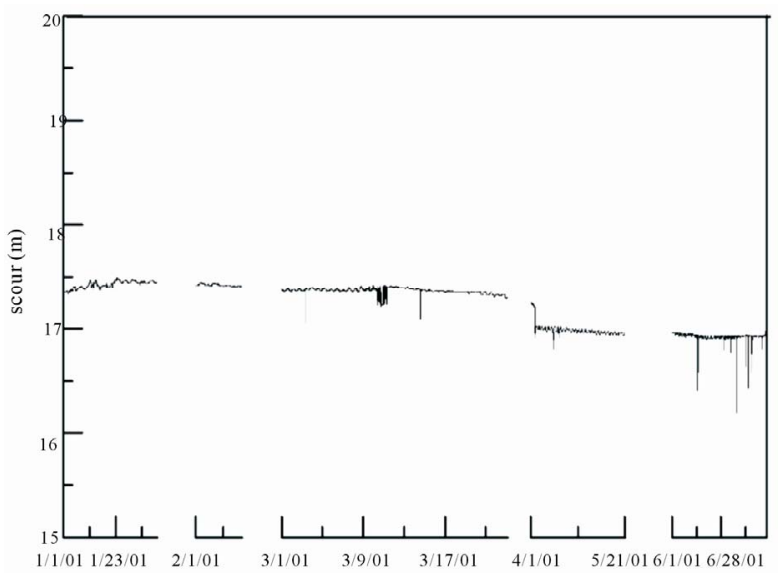

Figure 12. Scour depth variation at the pier P3.

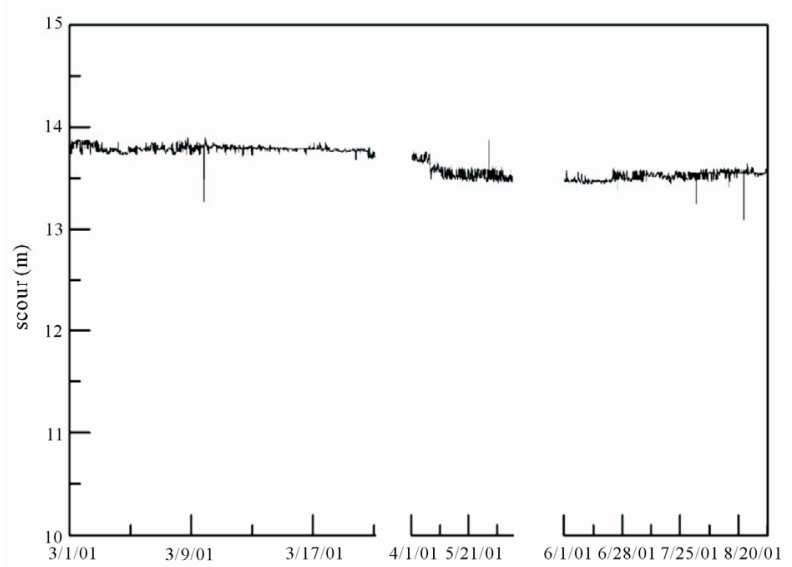

Figure 13. Scour depth variation at the pier P64.

First, the real-time bridge scouring data acquisition system developed had no difficulties in acquiring data and monitoring in remote labs over a long period of time over both river and costal bridge piers. The consistency of the quality data remarkably proved its credibility. In addition, by connecting the analyzing program with the 
actual on-site data through an unmanned remote control proved its effectiveness.

Second, compared to the conventional methods of collecting scour depth data, the real-time bridge scouring data acquisition system can measure geological changes instead of limited scour depth length. By monitoring changes in both depth length and geological changes, it opened up an entirely new vision in the field of bridge scouring research.

Third, because the real-time bridge scouring data acquisition system is able to monitor instantaneous changes in scouring, a warning system can be implemented. The real-time running warning system can allow preventative measures to be taken before the bridge collapses therefore saving human life.

Last, the supersonic Scourmeter, system, power source, and the wireless communication systems is developed and produced entirely in Korea. The quality and the reliability of the system are proven to be at the highest standards, and it will play a critical role bringing the Korean bridge scour research internationally.
The results from this study prove the efficiency and effectiveness of the real-time bridge scouring system. This study; however, only concentrated on the developmental side of the system. There are infinitely many uses for this system, and it is the hope from this study that a new level of bridge scouring research can be opened.

\section{References}

[1] J. Farden, “AIP Handbook of Modern Sensors,” AIP Press, New York, 1993.

[2] J. G. Kang, H. K. Yeo and S. J. Kim, “An Experimental Study on Tip Velocity and Downstream Recirculation Zone of Single Groyne Conditions,” KWRA, Vol. 38, No. 2, 2005, pp. 143-153.

[3] G. T. Park and Y. C. Im, "Interfacing of Sensor and BM PC,” Daeyoungsa, 1992.

[4] W. K. Yeo, "Study on Development of Simple System for Field Data Acquisition,” KWRA, 1997, pp. 249-260

[5] J. K. Lee, "Study on Field Scour Measurement for Protection and Maintenance,” KWRA, 1998. 